Af Ole Ellegaard, Konsulent,

tidl.forskningsbibliotekar, oleell@bib.sdu.dk

\title{
Online development in the Nordic countries
}

\section{EN ANMELDELSE}

\author{
A history of online information from the \\ 1960 s to the 'OOs and NORDINFO's role in \\ its development
}

\section{Baggrunden for antologien}

Ikke alle udgivelser med beskrivelse af et stykke bibliotekshistorie udkommer nødvendigvis som først planlagt. Dette gælder ikke mindst værket (Antologien): 'Online development in the Nordic countries, A history of online information from the 1960 s to the '00s and NORDINFO's role in its development'. Antologien blev udgivet, som en e-publikation på 249 sider, ved Helsingfors Universitet i 2018, med følgende editors: Elisabet Mickos $(\dagger)$, Teodora Oker-Blom, Marie Wallin, Lars Klasén, Aud Lamvik og Ulla Retlev (Oker-Blom et al. 2018).

Denne personkreds med base i de nordiske lande var alle tidligt involveret indenfor elektronisk informationssøgning, og antologien er et forsøg på at beskrive den korte, men hektiske periode, hvor denne service blev udbredt via dokumentationscentre. Hermed menes specifikt den service og den periode, hvor rekvireret informationssøgning i databaser blev udført af specialister ansat på offentlige biblioteker eller i private virksomheder. Teknisk set foregik søgningerne, via netværk, på fjerntliggende store computere eller såkaldte mainframes. De nye digitale databaser muliggjorde en langt mere effektiv og ikke mindst hurtigere søgning af informationer end via benyttelse af traditionelle papirbårne medier og arkiver.
Som nævnt i titlen tager beskrivelsen udgangspunkt i de nordiske lande, som har bidraget væsentligt til onlineudviklingen; men selvfølgelig refereres der også til forholdene specielt i USA, hvor de første større databaser blev digitaliseret sidst i 50erne og først 60erne. Disse databaser blev samlet og tilgængeliggjort hos såkaldte databaseværter, hvor amerikanske DIALOG var en af de tidligste. Enkelte af artiklerne er forfattet allerede omkring 2002, altså på et tidspunkt, hvor Internettet af mange blev det foretrukne informationsbærende medie. Faktisk kan man betragte denne periode som tidspunktet, hvor online æraen, i sin klassiske form, nærmede sig sin afslutning, og slutbrugerne selv tog over enten ved søgning i CD-ROM baserede medier eller gradvist i webbaserede databaser.

Selve ideen med at beskrive online historien tog sit udgangspunkt i et møde mellem Elisabet Mickos, som netop havde afsluttet sin ansættelse ved NORDINFOs(1) sekretariat i Finland og Marie Wallin fra 'Den Kongelige tekniske Højskoles Bibliotek' i Stockholm. De følte behov for at dokumentere, mens det stadig var muligt, perioden, hvor informationsspecialister og dokumentalister havde medvirket til at opbygge en helt ny online informationsservice. NORDINFO tilbød at finansiere projektet, men det led i første omgang skibbrud, da NORDINFO lukkede i 2004. Efter den 13 'th Nordiske loD konference i 2007 blev de hidtidige dele af manuskriptet lagt op på en server på Helsingfors Universitet. Herefter skete der ikke noget med materialet i det næste tiår, indtil den svenske informationsspecialist Lars Klasén, en af forfatterne, tog initiativ til at genoplive projektet. Den endelige antologi udkom i 2018 og rummer kapitler skrevet af de personer, som selv deltog aktivt indenfor online informationssøgning fra dets start indtil først i 00erne.

\section{Norden kommer online}

Saili Laitanen fra Finland giver i første kapitel en relativ kort introduktion til online informationssøgning, som den gradvist voksede frem fra starten af 60erne i specielt USA, men også den spæde opstart i de nordiske lande. Den personlige computer lå stadig mange år forude, så de første 'online' søgninger i databaser blev foretaget ved brug af fjernskrivere. Særlige søgesprog blev anvendt til at 'grave' information ud af databaserne, og Laitanen beskriver levende de mange tiltag, som måtte gøres, for at udgifterne ikke løb løbsk, da mange databaser blev faktureret på anvendt tid online. Antal poster som blev 'hentet' spillede også en rolle rent prismæssigt, så det var klart en fordel at forberede sine søgninger på forhånd. Præcist disse forhold samt tekniske 

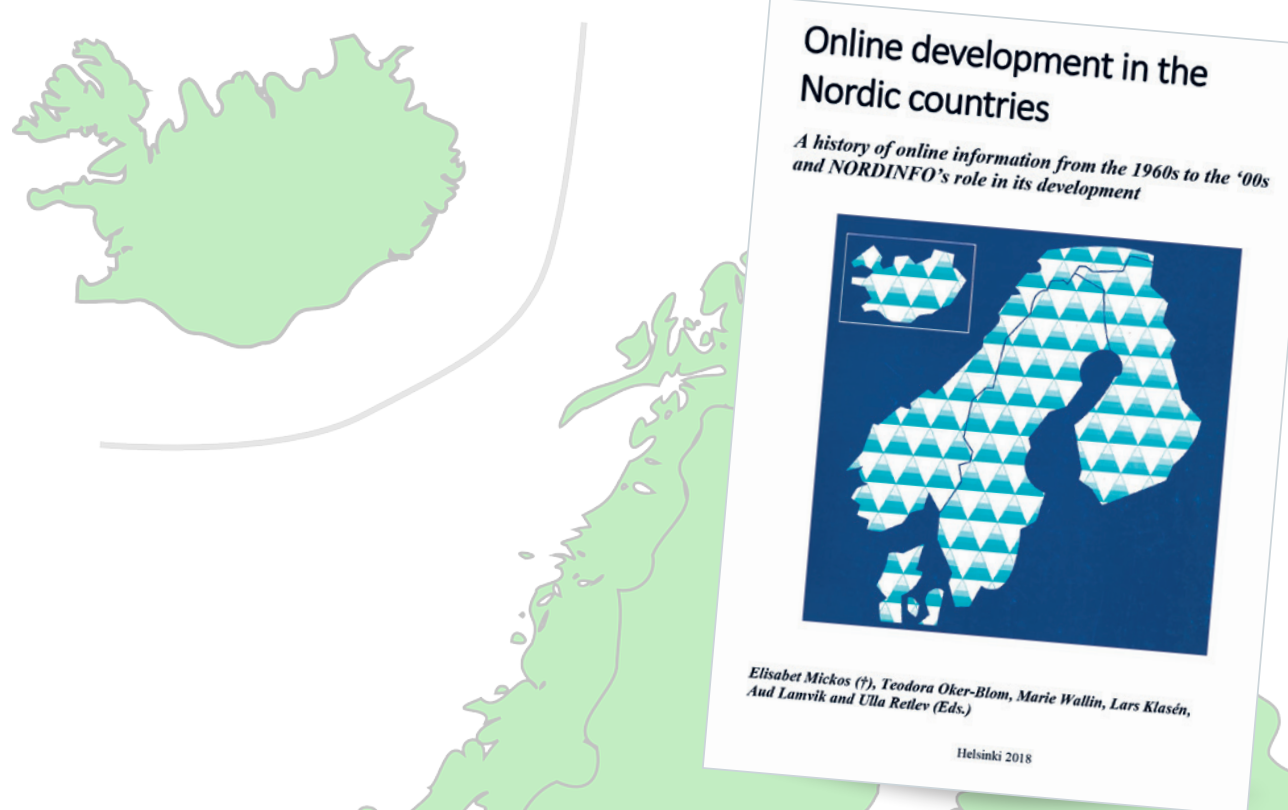

komplikationer var grunden til, at online søgning i starten primært var forbeholdt informationsprofessionelle. Antologien vender sig dog ret hurtigt mod de nordiske aspekter, og de følgende kapitler, redigeret af Theodora Oker-Blom, Finland og Aud Lamvik, Norge, står stærkt med en meget detaljeret dokumentation af de politiske og organisatoriske domæner, som online samarbejdet i Norden kom til at fungere under. Mange af disse organisationsstrukturer er for længst opløst eller har skiftet navn og funktion; men blandt de beskrevne navne, som NORDFORSK, NORDDOK og NORDINFO, skilte den sidste organisation sig ud som en væsentlig bidragyder til etableringen af online services i de nordiske lande.

I det hele taget er der, fra et dansk synspunkt, nyttig opsamling af viden om perioden at finde i antologien, selvom hovedvægten mange steder ligger på svenske forhold. Inge Berg Hansen (Tidligere leder af Danmarks Tekniske Bibliotek og DVJB) har bidraget med et kapital om NORDINFO, som gennem sin levetid kom til at spille en væsentlig koordinerende rolle indenfor feltet.

Kapitlerne kommer vidt omkring ikke mindst vedrørende den netværkstekniske del, hvor de første pionerer på området måtte slås med besværlige opkoblingsmuligheder og langsomme netværksforbindelser. Digitale netværk blev udviklet i perioden til transmission af data, men analoge telefonnetværk spillede dog fortsat en stor rolle. Beskrivelsen, redigeret af Aud Lamvik, af denne tekniske udvikling fylder en del og særlig interessant er det, at flere af forfatterne egenhændigt har bidraget til, at diverse netværk, såsom SCANNET, blev etableret i de nordiske lande. Særlig stabiliteten af SCANNET var ofte et issue ved diverse netværksmøder. Den daværende leder af dokumentationstjenesten ved DNLB, læge Holger Friis (1935-1984), kaldte det ofte ironisk for et 'skandalenet' ved disse møder. SCANNET blev senere erstattet af andre, mere driftsstabile, europæiske og transatlantiske netværk, hvor Internettet jo til sidst blev altdominerende.

Netop beskrivelserne af de vanskeligheder, som pionererne på området her i Norden mødte ved implementeringen af denne nye service, gør nogle af kapitlerne særligt læseværdige. Man fornemmer tydeligt, at mange af bidragsyderne var 'first movers' indenfor feltet, som med stor dedikation præsenterede online søgning 'live' for de ofte undrende deltagere ved møder og konferencer over hele Norden. Et publikum, som hidtil havde forbundet informationssøgning med talrige, tidskrævende opslag i trykte bibliografier og opslagsværker.

\section{Databaser og brugerne}

Et særligt kapitel, med introduktion af svenske Marie Wallin, er viet informationssystemer og databaser. Her fylder beretningen om MEDLARS selvfølgelig en del. Netop implementeringen af denne medicinske database, allerede fra midt 60erne, ved Karolinska Institut i Stockholm, blev en af spydspidserne indenfor informationssøgning i Sverige. Fra vinteren 1971/1972 blev online søgning, via telefon i basen Medline hos Karolinska, ligeledes et forbillede for en lignende, senere udvikling i norden.

Database produktion i de nordiske lande bliver berørt i et mindre afsnit ved Elisabeth Mickos. Udviklingen startede i det små med den svenske database Byggdok fra midt 70erne; men for brugerne blev udviklingen vanskeliggjort af de forskellige søgesprog og formater, som blev benyttet. Et forhold som først for alvor blev 'løst', via Internettet, med brug af de senere menubaserede søgeflader. Senere fulgte, med en massiv arbejdsindsats til konvertering og tilpasning af eksisterende data, en lang række andre baser, bl.a. blev mange bibliotekers kataloger digitaliseret. I Danmark udgav det daværende Dansk Diane Center en fortegnelse over tilgængelige databaser.

Men hvem benyttede sig af onlinetjenesterne? Dette omtales i et kapitel, redigeret af Elisabeth Mickos. 
Brugerne var selvfølgelig primært forskere og studerende på uddannelses og forskningsinstitutioner. Deres adgang var ofte via informationsspecialister eller såkaldte 'intermediære', ansat i dokumentationsafdelinger, som foretog søgninger i baserne på vegne af brugerne. Private virksomheder benyttede sig også af onlinemulighederne, men i Danmark har kun de allerstørste, såsom Novo, haft egen dokumentationsafdeling. Ser vi generelt på danske forhold, lå der et uforløst potentiale for virksomheders brug af online tjenester. Dette blev faktisk påpeget allerede i 1987, af Alex Gorski fra Dansk Diane Center, i en artikel i Børsens Nyhedsmagasin (Volquartz \& Gorski 1987).

\section{Infrastrukturen bag informationstjenesterne}

Et andet afsnit omtaler Dansk Diane Center og beskriver den væsentlige rolle, som centret fik for udbredelsen af videnskabelig dokumentation i Danmark. Centret, som senere som skiftede navn til InfoScan, blev den største af de nordiske centre, som blev etableret med statslige midler, for at fremme brugen af online informationssøgning, og har derfor fået et større afsnit i antologien, bl.a. forfattet af dets første direktør, Ulla Retlev.

Det påpeges, at blandt de nordiske centre opnåede Dansk Diane Center særlig stor succes. Dette skyldes dog ikke mindst den senere, karismatiske leder af centret gennem en årrække: Alex Gorski, som, ved mange møder, på underholdende vis, forstod at formidle om centrets aktiviteter. På sigt blev centrene dog udfaset i takt med Internettets fremkomst.

Inga Elding fra Sverige har et afsnit om de faglige foreninger eller brugergrupper, som opstod for at fremme informationsudvekslingen om den nye teknologi. Her blev Dansk Online Bruger Gruppe en af de første. I disse fora blev der i høj grad diskuteret netværksproblemer og sparret vedrørende erfaringer med de mange nye baser, som løbende kom til. I Danmark skete endda en opsplitning af onlinebru- gerne i en øst- og vestkreds, primært måske af transportmæssige grundedet var jo før en bro fik knyttet de to dele af landet sammen!

Hvor meget fyldte omkostningerne ved søgningerne i de forskellige institutioners budgetter og hvor udbredt blev onlinetjenesterne? Disse spørgsmål belyses, ud fra et nordisk samt et internationalt perspektiv, af den tidligere svenske informationsspecialist Lars Klasén, som bidrager med et stort, gennemarbejdet kapitel, hvor han bringer en række statistikker over graden af benyttelse, samt den omsætning onlineindustrien genererede. Han påviser, at benyttelse af online services, specielt indenfor STM området, er bremset op efter årtusindeskiftet. Særlig interessant og fremadskuende er hans diskussion om de mange forhold, bl.a. gratis tjenester, som har forårsaget denne udvikling,

\section{Informationssøgning i dag og supplerende læsning}

Antologien beskriver primært den brugerrekvirerede onlinesøgningens 'guldalder' frem til 2004, men kommer dog også, som tidligere nævnt, i de sidste kapitler kortfattet ind på den informationsrevolution som lå forude. En revolution, der radikalt ville ændre den måde, hvorpå information blev tilgængeliggjort og fremfundet. Dette indebar, at hele forretningsmodellen med 'pay per view' blev gradvis udfaset, og slutbrugerne overtog i stedet søgeprocessen i databaser, hvor bibliotekerne på forhånd havde tegnet abonnement. Tidligere tiders prismodel med indbygget 'minuttyranni' kom ikke tilbage. Slutbrugerne forblev i centrum og fik, som hovedregel, fri adgang til baserne. Der kom dog en ny bekymring på banen. Kunne brugerne udnytte baserne effektivt? Og blev de rigtige referencer fremfundet og bestilt?

Antologien har ikke kun sin berettigelse ud fra et historisk perspektiv, men rummer en fortælling om, at information ikke altid har været 'fri', universelt tilgængelig og 'gratis'.
Forhold som ikke nødvendigvis er indlysende for nutidens 'digitale indfødte', hvor 'nettet' er lige så naturligt et arbejdsredskab som tidligere tiders bøger, papir og blyant. Som forfatterne selv skriver i forordet:

'We hope that these glimpses of online history will trigger the memories of our colleagues and remind them of what we in the editorial team remembered as a challenging and pioneering period in Nordic online history. We also think that young people of today will enjoy glances into the past at a time when half of the population of the world is online this year 2018 according to the World Wide Web Foundation.

Et åbent spørgsmål er hvilke konsekvenser, det fik, fremadrettet, for selve dokumentationsprocessen (herunder brugen af søgemaskiner), bibliotekerne og brugerne i det hele taget, at de informationsprofessionelle ikke længere fungerede som 'gatekeepers' i processen? Dette har denne anmeldelses forfatter sammen med forskningsbibliotekar Mogens Kragsig Jensen og gæsteforsker, læge Johan Wallin forsøgt belyst i en netop udkommet artikel med titlen:'Online informationssøgning i en overgangstid med særligt henblik på det historiske forløb i et større dansk forskningsbibliotek' (Ellegaard et al. 2020).

Artiklen er publiceret i 'Nordic Journal of Library and Information Studies' og beskriver i større detaljer forholdene i Danmark og har, som case, lagt specielt vægt på forholdene ved Syddansk Universitetsbibliotek (tidl. Odense Universitetsbibliotek). I artiklen dokumenteres, bl.a. ud fra tilgængelig statistik, først væksten og senere faldet i antallet af online informationssøgninger ved dokumentationscentrene på de store forskningsbiblioteker. Vi diskuterer ligeledes, i artiklen, de omstillinger i bibliotekernes 'forretningsmodel' for informationssøgning, som nødvendigvis måtte blive en konsekvens af, at brugerne i langt højere grad var blevet selvhjulpne. 
Hvis man, udover antologien og artiklen i 'Nordic Journal of Library and Information Studies', ønsker et endnu mere detaljeret indblik i onlineindustriens fremkomst, både vedrørende databaseproduktion, den tekniske implementering af søgesystemer samt de udfordringer brugerne mødte, kan bogen 'A history of online information services 1963-1976' af Bourne \& Hahn (1987) varmt anbefales (Dette værk har dog særlig fokus på amerikanske forhold).

NORDINFO var en samarbejdsorganisation stiftet $i 1976$ af Nordisk Ministerråd med det formål, i regi af forskningsbibliotekerne, at fremme videnskabelig information og dokumentation.

\section{Organisationen understøttede i sin} levetid online services økonomisk men også ved at initiere projekter indenfor området. NORDINFO blev nedlagt i 2004 (Oker-Blom et al. 2018).

\section{Referencer}

Bourne, C. P. \& Hahn, T. B. (2003). A history of online information services 1963-1976. MIT Press. Cambridge. Mass.

Ellegaard, O., Jensen, M.K. \& Wallin, J. A. (2020) Online informationssøgning i en overgangstid med særligt henblik på forløbet $i$ et større dansk forskningsbibliotek. Nordic Journal of Library and Information Studies 1(1), 1-23.

Oker-Blom, T., Wallin, M., Klasén, L., Lamvik, A. \& Retlev, U. (Red.). (2018) Online development in the Nordic countries. University of Helsinki. http://doi. org/10.31885/2018.00003 Hentet 11 maj 2020. Volqvartz, N. T. \& Gorski, A. (1987). Danmark er bagud på databaser: kun få danske virksomheder søger systematisk på databaser i ind- og udland. Børsens Nyhedsmagasin. 3(13), 28-29.

\section{ORDFORKLARING}

Diane Centeret.

Dansk Diane Center, senere navneskift til Infoscan og endelig indlemmet under Statens Information (SI). Statsligt center i København, som blev etableret 1980 for at rådgive om online søgning i databaser. De første direktører var Ulla Retlev og Alex Gorski.

\section{DIALOG.}

Fremtrædende amerikansk databasevært. Etableret af Lockheed koncernen. Blev offentligt tilgængeligt fra 1972.

DNLB.

Danmarks Natur og Lægevidenskabelige Bibliotek. Nu sammenlagt med Det Kongelige Bibliotek.

DVJB.

Danmarks Veterinær- og Jordbrugsbibliotek. Nu under Københavns Universitet

\section{MEDLARS.}

Medical Literature Analysis and Retrieval System. Søgesystem til medicinske databaser.

\section{MEDLINE.}

Stor biomedicinsk, bibliografisk database som udgives af National Library of Medicine, USA. Anvendes i dag primært via søgefladen: PUBMED.

NORDDOK.

Nordisk Komite for Information og Dokumentation

\section{NORDFORSK.}

Skandinavisk Råd for anvendt Forskning, i funktion til 1974; herefter Nordisk Samarbejdsorganisation for anvendt Forskning.

\section{NORDINFO.}

Nordisk Råd for Videnskabelig Information (1976-2003)

Nordiske loD. Konference med information og dokumentation som tema. Blev afholdt på skift i de nordiske lande.

\section{SCANNET.}

Skandinavisk datanetværk.

STM.

Science, Teknologi og Medicin

Eksempler på tidlige milepæle i online informationssøgningens historie (Bourne 2003, Oker-Blom 2018):

1963, Science Citation Index etableres

i USA af Eugene Garfield

1970, Danmarks Tekniske Bibliotek, DTB tilbyder SDI profiler i databaser

1972, Karolinska Institut i Sverige udbyder databasen MEDLINE online

1972, Databaseværten DIALOG bliver fuldt operationel i USA

1974, Danmarks Natur og Lægevidenskabelige Bibliotek, DNLB tilbyder online søgninger

1980, Journal of Medical Chemistry bliver første online tidsskrift i fuld tekst

1985, Det engelske firma Silverplatter udgiver MEDLINE og andre baser på CD-ROM

1989, Tim Berners-Lee ved CERN etablerer fundamentet for WWW

1994, Dybkjær rapporten 'Infosamfundet år 2000' udgives

1998, DEFF, Danmarks Elektroniske Forskningsbibliotek dannes 